\title{
Induksi Teknologi Media Pembelajaran Interaktif Sebagai Sarana Peningkatan Proses Pembelajaran dan Manajemen Evaluasi Siswa
}

\author{
Indah Nofikasari $^{1}$, Fajar Suryani ${ }^{2}$, Margareta Evi Yuliana ${ }^{3}$ \\ ${ }^{1,2,3}$ Universitas Duta Bangsa Surakarta; J1. Bhayangkara 55 Surakarta,0271719552 \\ ${ }^{1,2,3}$ Fakultas Ilmu Komputer Program Studi Sistem Informasi, Universitas Duta Bangsa \\ e-mail : ${ }^{1}$ indahnofika.stmikdb@gmail.com, ${ }^{2}$ fajar_suryani@udb.ac.id, \\ margareta_evi@udb.ac.id
}

\begin{abstract}
Abstrak
Tujuan kegiatan pengabdian ini adalah melakukan induksi teknologi yang terdiri dari Aplikasi Pembelajaran Interaktif dan Menarik berbasis multimedia serta manajemen administrasi hasil evaluasi siswa. Kegiatan ini untuk meningkatkan proses pembelajaran dan manajemen evaluasi siswa. Kegiatan Induksi teknologi dilakukan dalam lima tahap yaitu (1) Penyusunan Materi, (2) Pelatihan, (3) Persiapan peralatan, Desain Sistem dan Implementasi Program, (4) Pendampingan dan (5) Monitoring. Pendekatan yang dilakukan untuk proses penyusunan materi dan pelatihan adalah pendekatan konsep proses pembelajaran interaktif berbasis multimedia. Pendekatan yang digunakan untuk proses pendampingan adalah pendekatan Project pembuatan materi pembelajaran interaktif berbasis multimedia. Pendekatan yang digunakan untuk kegiatan monitoring adalah problem solving. Kegiatan ini mitra dikenalkan dengan teknologi dan cara menggunakan aplikasi yang akan diimplementasikan dan manajemen evaluasi hasil pembelajaran siswa menggunakan Microsoft excel dan Microsoft word. Proses implementasi media pembelajaran interaktif yang terdiri dari pembuatan aplikasi pembelajaran berbasis multimedia dan manajemen evaluasi hasil pembelajaran siswa akan dilakukan oleh mitra dengan pendampingan dari tim pengabdian. Kegiatan pengabdian ini adalah implementasi media pembelajaran interaktif berbasis multimedia yang meliputi pembuatan aplikasi pembelajaran interaktif berbasis multimedia, mengedit gambar dan video, publish aplikasi ke media penyimpanan dan perbaikan manajemen evaluasi hasil pembelajaran siswa.
\end{abstract}

Kata kunci : Pembelajaran, Interaktif, Evaluasi, Manajemen

\section{PENDAHULUAN}

Taman kanak-kanak (TK) merupakan jenjang pendidikan anak usia dini (yakni usia dibawah enam tahun) dalam bentuk pendidikan formal. Kurikulum TK ditekankan pada pemberian rangsangan pendidikan untuk membantu pertumbuhan dan perkembangan jasmani dan rohani agar anak memiliki kesiapan dalam memasuki pendidikan lebih lanjut. Penyampaian pembelajaran yang baik dan tepat akan menunjang kemajuan kecerdasan anak. Terutama pada kegiatan belajar mengajar, segala aktifitas komunikasi dan penyampaian materi pelajaran harus disampaikan dengan semenarik mungkin agar anak mudah dalam menangkap materi dan lebih mudah untuk menghafalkan materi dengan baik.

Pendidikan anak usia dini memiliki fungsi utama mengembangkan semua aspek perkembangan anak, meliputi perkembangan kognitif, bahasa, fisik (motorik kasar dan 
halus), sosial dan emosional. Berbagai hasil penelitian menunjukkan bahwa ada hubungan yang sangat kuat antara perkembangan yang dialami anak pada usia dini dengan keberhasilan mereka dalam kehidupan selanjutnya. Misalnya, anak-anak yang hidup dalam lingkungan (baik di rumah maupun di KB atau TK) yang kaya interaksi dengan menggunakan bahasa yang baik dan benar akan terbiasa mendengarkan dan mengucapkan kata-kata dengan benar, sehingga ketika mereka masuk sekolah, mereka sudah mempunyai modal untuk membaca. Sehubungan dengan fungsi-fungsi yang telah dipaparkan tersebut, maka tujuan pendidikan anak usia dini dapat dirumuskan sebagai berikut :

1. Memberikan pengasuhan dan pembimbingan yang memungkinkan anak usia dini tumbuh dan berkembang sesuai dengan usia dan potensinya.

2. Mengidentifikasi penyimpangan yang mungkin terjadi, sehingga jika terjadi penyimpangan, dapat dilakukan intervensi dini.

3. Menyediakan pengalaman yang beranekaragam dan mengasyikkan bagi anak usia dini, yang memungkinkan mereka mengembangkan potensi dalam berbagai bidang, sehingga siap untuk mengikuti pendidikan pada jenjang sekolah dasar (SD).

Media adalah segala sesuatu yang digunakan untuk menyalurkan pesan, dapat merangsang pikiran, perasaan, minat, serta perhatian anak sehingga proses belajar terjadi. Media pembelajaran yaitu suatu perangkat pembelajaran multimedia yang digunakan oleh guru untuk menyampaikan materi agar lebih menarik, sehingga anak dapat focus dan tertarik dengan materi yang disampaikan. Karena itu, materi yang disampaikan tidak membosankan dan dapat ditangkap dengan baik oleh anak [1].

Komputer multimedia mempunyai peranan yang sangat penting dalam bidang pendidikan. Ini terbukti dengan adanya produksi aplikasi multimedia dalam bentuk CD pembelajaran yang telah banyak beredar di pasaran saat ini. CD pembelajaran sendiri ada banyak macam, baik yang bersifat interaktif dan non-interaktif [2].

Model pembelajaran berbasis multimedia interaktif dimaksudkan untuk membuat pembelajaran menjadi lebih menarik dan materi yang bersifat abstrak dapat divisualisas dalam media animasi sesuai dengan kondisi actual di lapangan mengikuti perkembangan ilmu dan teknologi yang terus berkembang sehingga motivasis mahasiswa untuk belajar dan membangun pengetahuannya menjadi lebih mudah untuk dillakukan [3].

Media memiliki fungsi sebagai pembawa informasi dari sumber (guru) menuju penerima (siswa). Sedangkan metode adalah prosedur untuk membantu siswa dalam menerima dan mengolah informasi guna mencapai tujuan pembelajaran [1].

Media Film Animasi ini pada umumnya sangat disenangi oleh anak-anak karena mengandung karakter gambar animasi yang menarik [4].

PAUD Aisyiyah Al-Hasanah yang beralamat di Gronong RT. 03 RW. 05 Kelurahan Mandan Kecamatan Sukoharjo Kabupaten Sukoharjo. PAUD Aisyiyah Al-Hasanah dengan status sekolah swasta jenjang pendidikan KB dengan NPSN 69909635 dibawah naungan Kementrian Pendidikan dan Kebudayaan dengan No. SK. Pendirian 411.3/670/2012 Tanggal SK. Pendirian 21 Desember 2012, dengan No. SK . Operasional 411.3/670/2012 dan Tanggal Operasioal 21 Desember 2012 [5].

Berdasarkan observasi dan wawancara yang dilakukan oleh Tim PKM kepada mitra bahwa permasalahaan yang dihadapi mitra adalah dalam penyampaian materi kepada siswa yaitu menyampaikan materi dalam pembelajaran yang dilakukan pada Mitra masih menggunakan gambar atau poster untuk media visualnya dan metode ceramah untuk penyampaian informasi dari buah tersebut. Hal tersebut terkadang anak tidak focus dan kurang berkonsentrasi. Sehingga berdampak pula pada proses belajar mengajar. Oleh sebab itu, Tim PKM dan mitra sepakat untuk bekerjasama untuk memanfaatkan Media Pembelajaran Interaktif, Atraktif, Sistematis, Menarik dan Ramah Berbasis Multimedia pada Anak Usia Dini. 
Proses pembelajaran kepada siswa yang diterapkan masih menggunakan metode konvensional yaitu menggunakan gambar atau poster buah untuk media visualnya dan metode ceramah untuk penyampaian informasi dari buah tersebut.

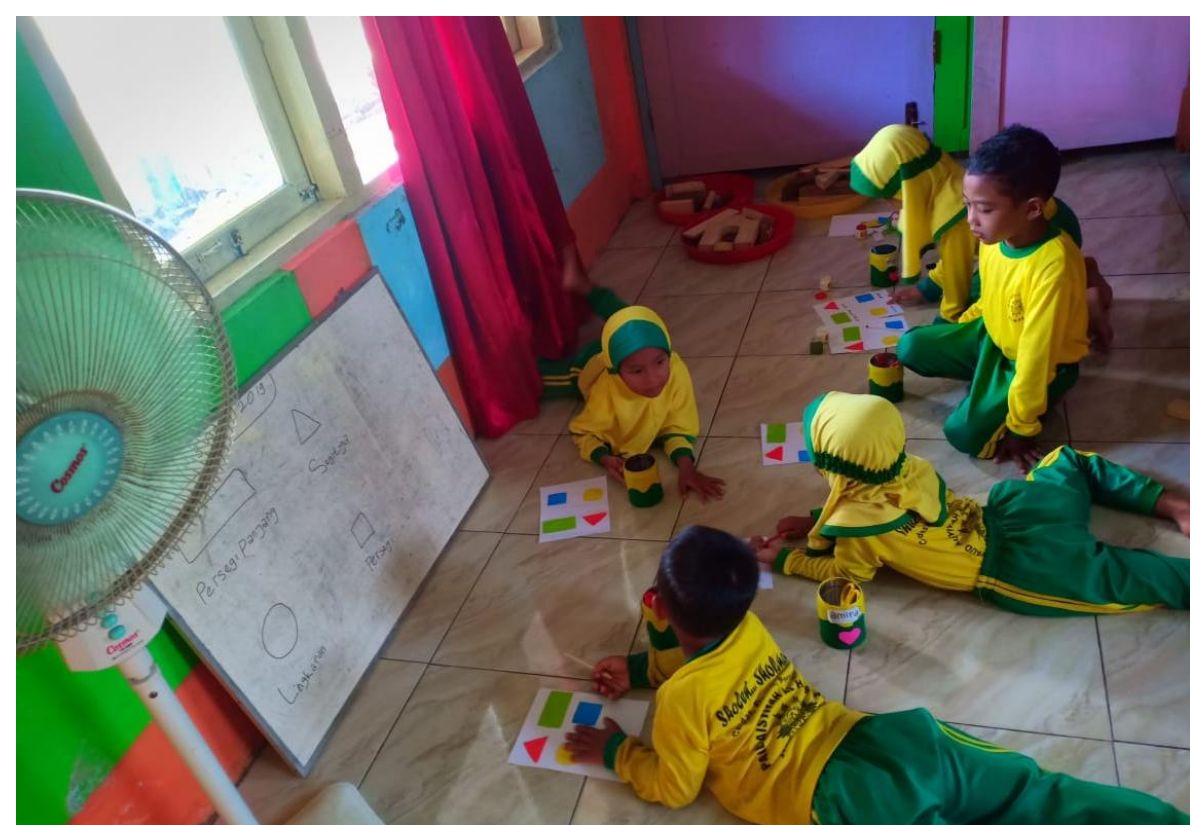

Gambar 1 Proses Pembelajaran di PAUD Aisiyah Al-Hasanah

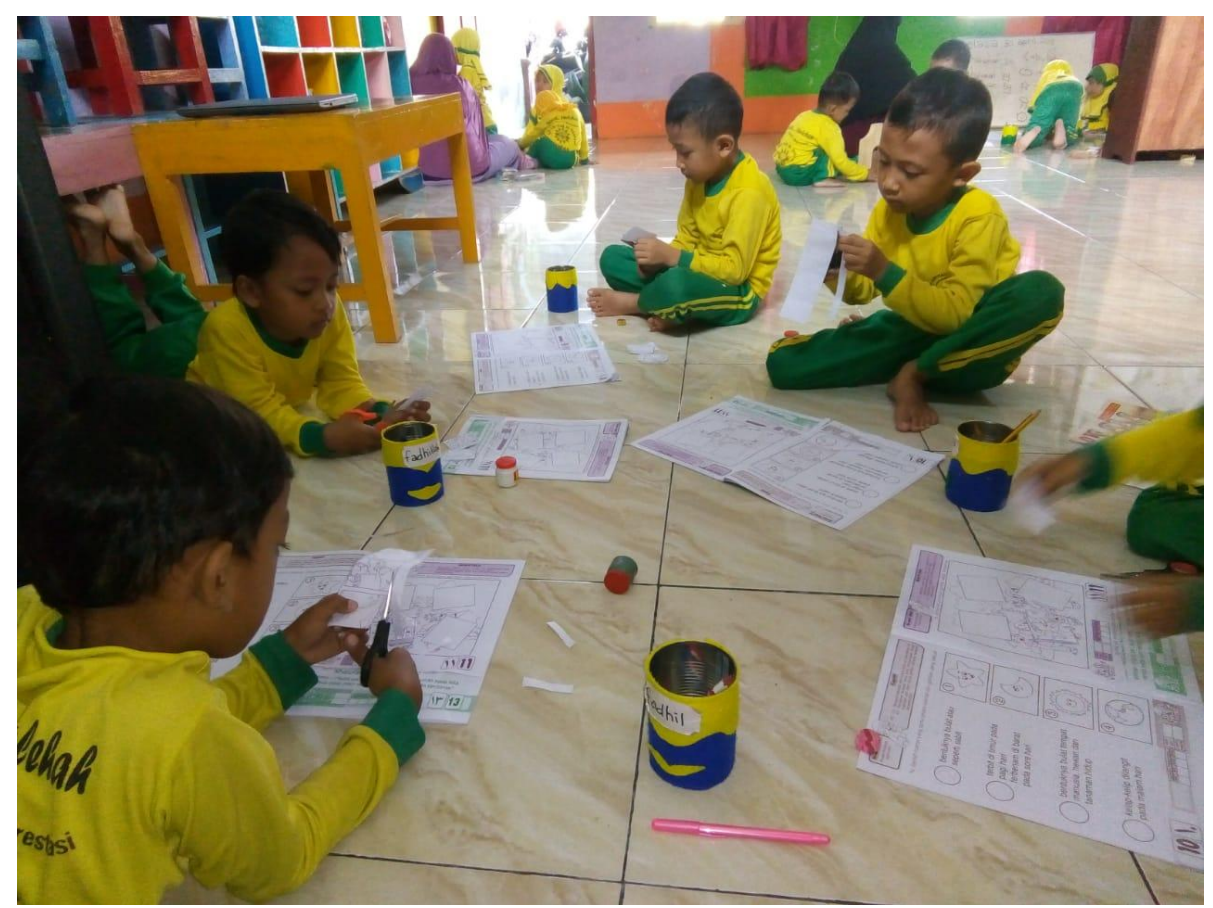

Gambar 2 Proses Pembelajaran di PAUD Aisiyah Al-Hasanah

Alternatif solusi permasalahan tersebut di atas adalah dengan pemanfaatan Media Pembelajaran Interaktif, atraktif, sistematis, menarik dan ramah Berbasis Multimedia yang dapat memudahkan guru dalam menyampaikan materi pembelajaran serta dengan tampilan yang menarik dan interaktif sehingga anak didik dapat memahami penyampaian guru dengan baik. 


\section{METODE}

Metode pelaksanaan kegiatanterdiri dari penyusunan materi, pelatihan, pendampingan dan monitoring. Pendekatan yang dilakukan untuk proses penyusunan materi dan pelatihan adalah pendekatan konsep-proses. Pendekatan konsep proses menekankan kepada konsep pembelajaran interaktif dan manajemen administrasi hasil evaluasi siswa yang terkomputerisasi setelah itu mitra diajak untuk mengetahui cara implementasi Aplikasi Pembelajaran Interaktif dan manajemen administrasi hasil evaluasi siswa melalui proses pelatihan. Pendekatan yang digunakan untuk proses pendampingan adalah pendekatan Project pembuatan materi pembelajaran interaktif berbasis multimedia. Mitra dan tim pengabdian terjun bersama-sama untuk membangun Aplikasi Pembelajaran Interaktif, melakukan editing gambar, editing video dan suara dan melakukan perbaikan manajemen administrasi hasil evaluasi siswa secara komputerisasi. Pendekatan yang digunakan untuk kegiatan monitoring adalah problem solving. Tim pengabdian akan terus melakukan pendampingan, pemantauan dan evaluasi untuk membantu mitra mengatasi kendala yang terjadi pada proses implementasi aplikasi dan pemeliharaannya.

\section{HASIL DAN PEMBAHASAN}

Kegiatan Pengabdian Masyarakat ini mitra diberikan pelatihan pemanfaatan media pembelajaran interaktif. Pelatihan meliputi teknik pemanfaatan media pembelajaran interaktif, mendesain media pembelajaran interaktif, atraktif dan sistematis, membuat media pembelajaran interaktif, atraktif, sistematis, menarik dan ramah, mengedit gambar, mengedit video dan suara. Mitra juga mengikuti untuk pelatihan untuk manajemen administrasi hasil evaluasi siswa berbasis komputerisasi sederhana.

Tahap pelatihan mitra akan menjadi pusat pelaksanaan implementasi program. mitra membangun media pembelajaran interaktif berbasis multimedia dan manajemen administrasi hasil evaluasi siswa berbasis komputerisasi sederhana dengan pendampingan dari tim pengabdian. Proses implementasi media pembelajaran interaktif berbasis multimedia dan manajemen administrasi hasil evaluasi siswa berbasis komputerisasi juga dilakukan mitra bersama tim pengabdian.

Pelatihan pengembangan teknik pembelajaran interaktif berbasis multimedia dilakukan dengan mengembangkan aplikasi pembelajaran interaktif, atraktif, sistematis, menarik dan amah. Materi pelatihan mengacu pada modul yang telah disusun sebelumnya. Pelatihan akan dilakukan selama lima hari dengan panjang sesi pelatihan adalah empat jam.

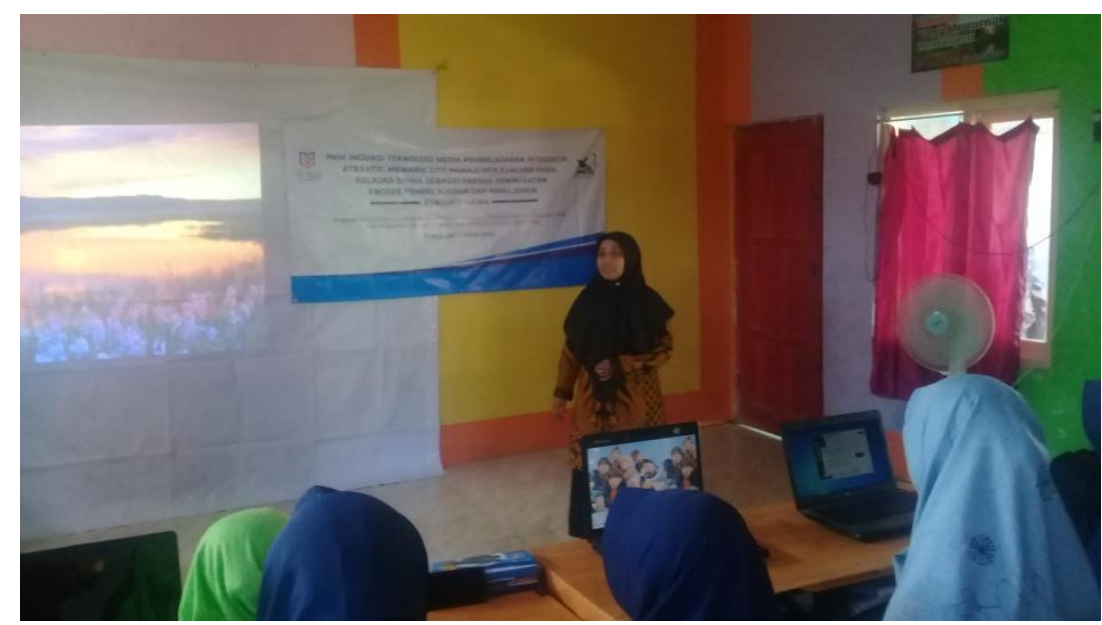

Gambar 3 Kegiatan Pengabdian 


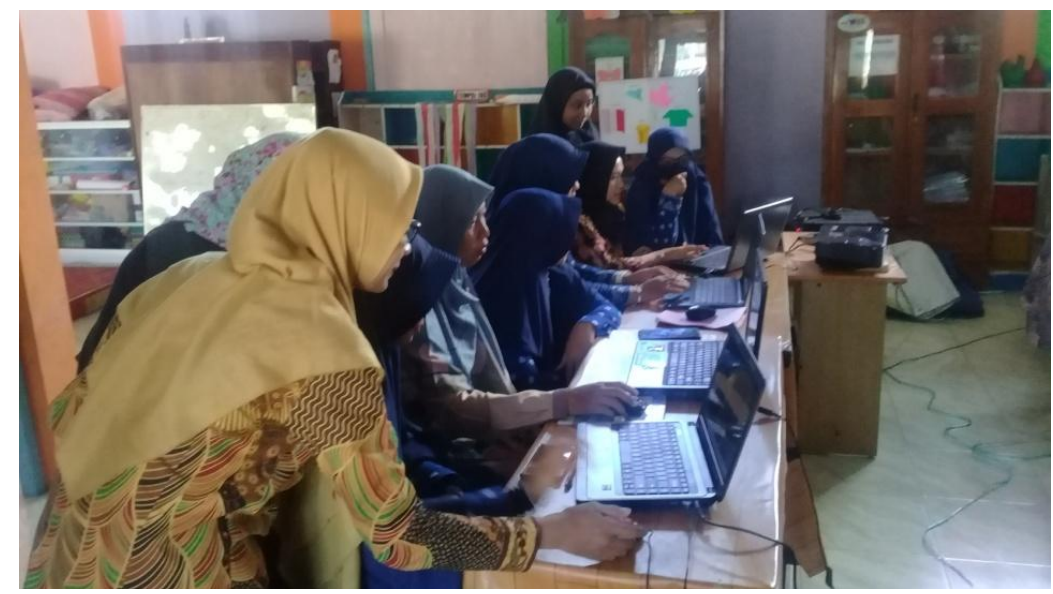

Gambar 4 Kegiatan Pengabdian

Pelatihan manajemen administrasi hasil evaluasi siswa mengacu pada modul yang telah disusun sebelumnya. Pelatihan akan dilakukan selama dua hari dengan panjang sesi pelatihan adalah empat jam.

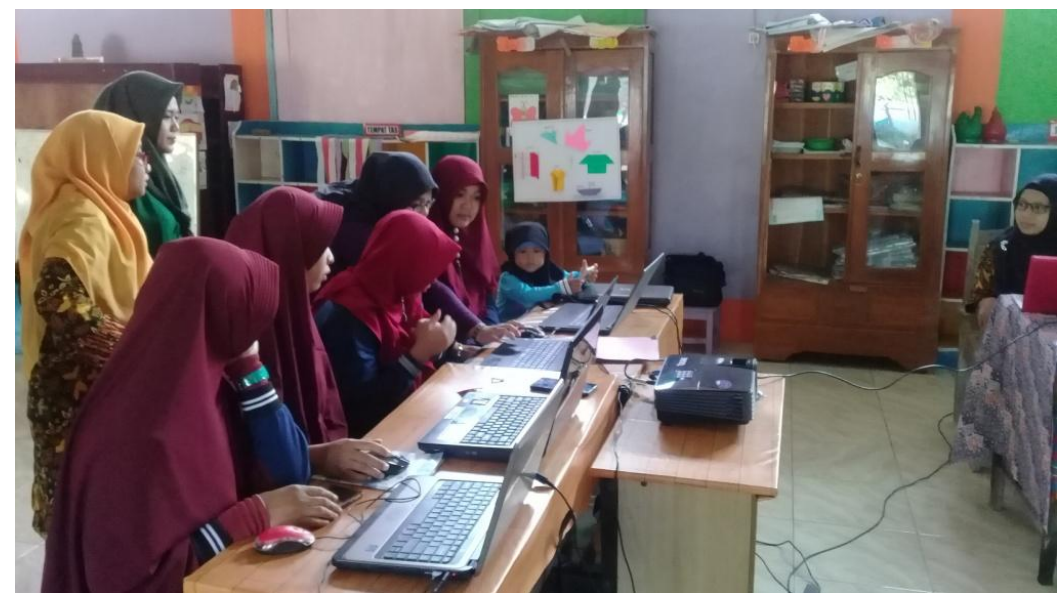

Gambar 5 Kegiatan Pengabdian

Pendampingan dilakukan kepada mitra untuk penerapan media pembelajaran interaktif yang menarik dan mudah dipahami siswa. Tim juga melakukan pendampingan dengan membimbing mitra untuk manajemen administrasi hasil evaluasi siswa berbasis komputerisasi. Tim pengabdian akan melakukan pemantauan secara berkala dan berkelanjutan untuk mengatasi kesulitan yang dialami mitra dan melihat dampak pengembangan media pembelajaran interaktif berbasis multimedia terhadap peningkatan hasil belajar siswa. 


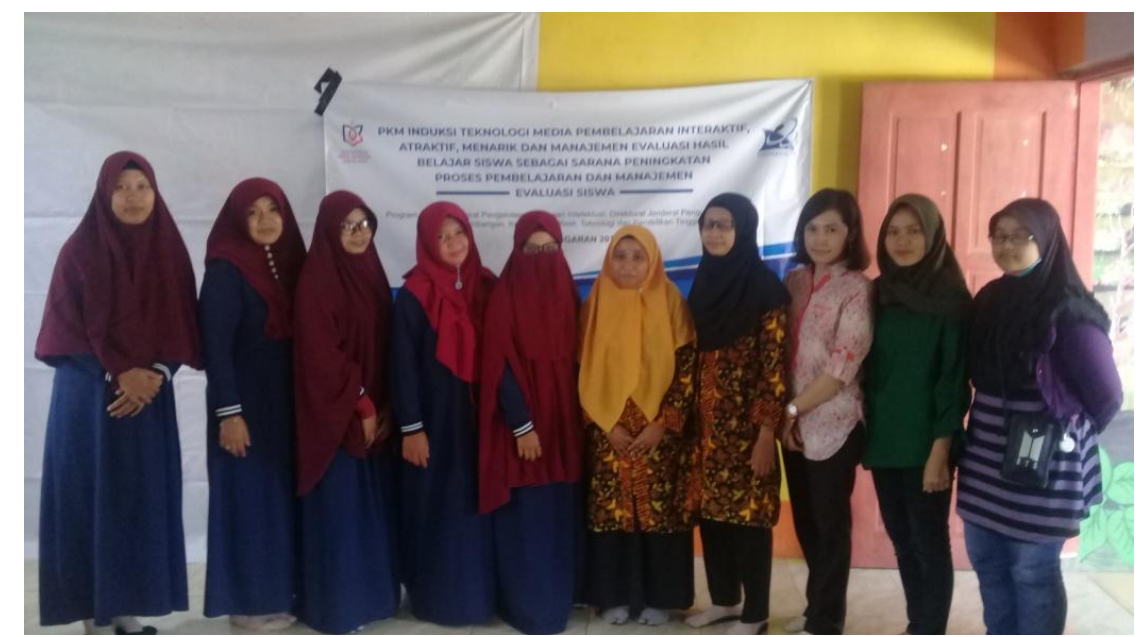

Gambar 6 Kegiatan Pengabdian

\section{KESIMPULAN}

Kegiatan PkM Induksi Teknologi Media Pembelajaran Interaktif Sebagai Sarana Peningkatan Proses Pembelajaran dan Manajemen Evaluasi Siswa meliputi (1) Pelatihan pengembangan media pembelajaran interaktif berbasis multimedia, (2) Pelatihan manajemen administrasi hasil evaluasi siswa dan (3) selanjutnya dapat dilakukan Persiapan Peralatan, Konfigurasi Sistem dan Implementasi Program.

\section{SARAN}

Kegiatan pengabdian ini telah dilaksanakan dengan melatih mitra mengenai Induksi Teknologi Media Pembelajaran Interaktif Sebagai Sarana Peningkatan Proses Pembelajaran dan Manajemen Evaluasi Siswa. Dalam kegiatan ini ditemukan bahwa mitra terdapat permasalahan mengenai pengeleloaan manajemen pembayaran siswa, untuk itu dapat dilakukan penelitian selanjutnya mengenai manajemen pengelolaan pembayaran siswa yang tepat yang dapat dilakukan pada mitra yaitu TK Aisiyah Al_Hasanah Sukoharjo.

\section{UCAPAN TERIMA KASIH}

Terimakasih kepada Direktorat Riset Pengabdian Masyarakat Kementerian Riset, Teknologi dan Pendidikan Tinggi yang telah memberikan pendanaan kegiatan Program Kemitraan Masyarakat ini pada tahun 2019. Ucapan terimakasih juga disampaikan kepada seluruh civitas Universitas Duta Bangsa yang telah mendukung terlaksananya Program Kemitraan Masyarakat ini. Tidak lupa, terimakasih kepada Kepala Sekolah dan Guru PAUD Aisiyah Al-Hasanah atas kerjasamanya. 


\section{DAFTAR PUSTAKA}

[1] Daryanto. 2013, Media Pembelajaran, Vol. 1, Ed. 1, Gava Media, Yogyakarta

[2] Hanif Al Fatta., 2010, Aplikasi Multimedia Interaktif Pembelajaran IPA untuk Sekolah Dasar Kelas VI, Jurnal DASI, Vol. 11, No. 2, Juni 2010; http://litbang.amikom.ac.id/index.php/main/page/137/publikasi-jurnal-dasi

[3] Ali, M, 2009, Pengembangan Media Pembelajaran Interaktif Mata Kuliah Medan Elektromagnetik, Jurnal Edukasi, @Elektro 5(1): 11-18

[4] Purwanto, E., \& Yuliana, M. E. (2016). Penerapan Animasi Pertunjukan Wayang sebagai Media Pendidikan Budi Pekerti dan Memperkenalkan Budaya Bangsa kepada Anak Usia Dini, Jurnal SAINSTECH Politeknik Indonusa Surakarta, 1(6), 21-31

[5] Data Referensi Kementrian Pendidikan dan Kebudayaan, Identitas Satuan Pendidikan / Lembaga, http://referensi.data.kemdikbud.go.id, diakses tanggal 23 Maret 2018 